COSTA, L.C.B.; CORRÊA, R.M.; CARDOSO, J.C.W.; PINTO, J.E.B.P.; BERTOLUCCI, S.K.V.; FERRI, P.H. Secagem e fragmentação da matéria seca no rendimento e composição do óleo essencial de capim-limão. Horticultura Brasileira, Brasília, v.23, n.4, p.956-959, out-dez 2005.

\title{
Secagem e fragmentação da matéria seca no rendimento e composição do óleo essencial de capim-limão
}

\author{
Larissa C. do B. Costa ${ }^{1}$; Ricardo M. Corrêa ${ }^{2}$; Júlio César W. Cardoso²; José Eduardo B.P. Pinto²; Suzan \\ K.V. Bertolucci² ${ }^{2}$ Pedro H. Ferri ${ }^{3}$ \\ ${ }^{1}$ UESC, Depto. Ciências Biológicas, 45650-000 Ilhéus-BA; ${ }^{2}$ UFLA, Depto. Agricultura, 37200-000 Lavras-MG; ${ }^{3}$ UFG, Instituto de \\ Química, Goiânia-GO
}

\section{RESUMO}

Este estudo foi conduzido com objetivo de determinar o tipo de secagem e a fragmentação das folhas de capim-limão para otimizar o rendimento extrativo do óleo essencial. Foram estabelecidos 6 tratamentos com 2 tipos de secagem (estufa de ventilação forçada a $40^{\circ} \mathrm{C}$ e sala com desumidificador) e 3 tamanhos de fragmentos das folhas secas (pulverização em moinho, fragmentos com 1 e com 20 $\mathrm{cm}$ de comprimento), com 4 repetições. O óleo essencial foi extraído por hidrodestilação durante 2 horas. O maior rendimento de óleo essencial foi obtido com o material seco na sala com desumidificador, não havendo diferenças significativas para os tamanhos da folha. $\mathrm{O}$ componente mais abundante no óleo essencial foi o citral que também apresentou as maiores concentrações nas folhas secas em desumidificador.

Palavras-chave: Cymbopogon citratus, planta medicinal, pós-colheita, secagem, moagem.

\begin{abstract}
Yield and composition of essential oil of lemongrass in different drying and fragmentation conditions

In this study the drying and fragmentation conditions of lemongrass leaves were determined, to increase the essential oil yield. Four replications of six treatments were studied with 2 drying methodologies (oven-drying at $40^{\circ} \mathrm{C}$ and room temperature using moisture dryer) and 3 fragmentation sizes (powder obtained in mill, $1 \mathrm{~cm}$ and $20 \mathrm{~cm}$ fragments). The essential oil was extracted in Clevenger's modified apparatus during 2 hours. The higher essential oil yield and citral content was obtained with the leaves dried under room temperature using moisture dryer, with no significant differences in the fragmentation sizes.
\end{abstract}

Keywords: Cymbopogon citratus, medicinal plant, post-harvest, drying, miller.

\section{(Recebido para publicação em 17 de fevereiro de 2005 e aceito em 3 de agosto de 2005)}

$C$ ymbopogon citratus (D.C.) Stapf é uma espécie originária da Índia e largamente distribuída por vários países tropicais, entre eles o Brasil, onde assume diferentes sinonímias conforme a região onde se encontra: capim-limão (MG), capim-santo (BA), erva-cidreira (SP) e outros como capim-catinga, capim-de-cheiro, capim-cidrão, capimcidrilho, capim-cidró e capim-ciri. Pertence à família Poaceae e se constitui em uma erva perene, que forma touceiras compactas e robustas de até $1,2 \mathrm{~m}$ de altura, com rizoma semi-subterrâneo.

O chá das folhas da espécie tem larga utilização popular para nervosismo, febre, tosse, dores diversas (dor de cabeça, abdominais, reumáticas) e alterações digestivas como dispepsia e flatulência. Também é aproveitada com finalidades agronômicas para composição de cercas-vivas e na contenção de encostas para evitar a erosão, mas a sua maior importância econômica reside na produção do seu óleo essencial, rico em citral e largamente utilizado na indústria de alimentos e cosméticos.
Em órgãos isolados o citral apresentou efeito antiespasmódico, tanto no tecido uterino como no intestinal, entretanto não mostrou atividade sobre a musculatura esquelética e cardíaca (FERREIRA, 1984). Estudos sugerem que a atividade antibacteriana de $C$. citratus reside principalmente nos componentes $\alpha$ - e $\beta$-citral presentes no óleo (ONAWUNMI et al., 1984). Suas atividades antimicrobianas e antifúngicas foram comprovadas em 22 espécies de microrganismos, além da propriedade inseticida, principalmente larvicida, bem como, repelente de insetos (SOUZA et al., 1991).

Rocha et al. (2000) estudando o efeito da temperatura de secagem sobre o rendimento e a composição química do óleo essencial de Cymbopogon winterianus, encontraram os melhores resultados para o tempo de secagem e rendimento de óleo na temperatura de $60^{\circ} \mathrm{C}$ e grande variação quantitativa do neral em função das diferentes temperaturas testadas $\left(30 ; 40 ; 50 ; 60\right.$ e $\left.70^{\circ} \mathrm{C}\right)$. Em Mentha piperita, observou-se que a elevação da temperatura de secagem de 40 para $60^{\circ} \mathrm{C}$ e depois para $80^{\circ} \mathrm{C}$ provocou uma grande redução no conteúdo de óleo essencial, além de afetar também a sua composição, diminuindo o conteúdo de 1,8 cineol e citronelal até $80^{\circ} \mathrm{C}$ e aumentando os conteúdos de mentol e neomentol até $60^{\circ} \mathrm{C}$ (BLANCO et al., 2002a). Comportamento semelhante de redução do teor de óleo essencial com o aumento da temperatura de secagem também foi observado em Rosmarinus officinalis, verificando-se alteração da composição química entre 60 e $80^{\circ} \mathrm{C}$ (BLANCO et al., 2002b). Martins (1998) relata que temperaturas superiores a $45^{\circ} \mathrm{C}$ danificam os órgãos vegetais e seu conteúdo, pois causam uma "cocção" das plantas e não uma secagem.

A secagem das plantas aromáticas e medicinais visa minimizar a perda de princípios ativos e retardar a sua deterioração em decorrência da redução da atividade enzimática, permitindo a conservação das plantas por um período maior para a sua posterior 
comercialização e uso. Além disso, os processos de secagem afetam sobremaneira o rendimento e a composição química das espécies, especialmente as aromáticas por possuírem substâncias muito voláteis (VON HERTWIG, 1991) Corrêa et al. (2004), estudando rendimento de óleo essencial sob diferentes métodos de secagem, observaram que a secagem à sobra mista (sol e sombra) e secador solar proporcionaram maior rendimento de óleo em comparação à secagem em estufa a $35^{\circ} \mathrm{C}$.

Em contrapartida, Rosal et al. (2004) estudando o efeito de diferentes métodos de secagem no teor de óleo essencial de folhas e inflorescências de basilicão (Ocimum basilicum), verificaram que a secagem em estufa a $35^{\circ} \mathrm{C}$ permitiu maior teor de óleo essencial nesta espécie, em comparação com a secagem em desumidificador.

O estado de fragmentação do material vegetal também tem sua importância para a otimização extrativa, pois quanto maior a divisão, mais expostos estarão os princípios ativos. Como os óleos essenciais localizam-se em estruturas internas e/ou externas diversas, a fragmentação do material vegetal pode influenciar diretamente no rendimento extrativo. Silva et al. (2004), estudando os teores de óleos essenciais de folhas de cidrão (Aloysia triphylla), frescas e secas em diferentes tamanhos de fragmentos verificaram que folhas inteiras secas, frescas inteiras e frescas processadas em liquidificador não apresentaram diferenças no teor de óleo essencial. Porém as folhas secas trituradas em moinho apresentaram o menor rendimento no ensaio

Os teores e a composição química dos constituintes voláteis das plantas aromáticas sofrem influência de diversos fatores, dentre os quais destacam-se o método de secagem e o processo extrativo empregado. Desde que toda a comercialização e armazenamento do capim-limão só podem ser realizados com o material seco, elaborou-se este estudo, com o objetivo de determinar o rendimento de óleo essencial das folhas de capimlimão submetidas a dois métodos de secagem e fragmentadas em três tamanhos.

\section{MATERIAL E MÉTODOS}

O experimento foi conduzido de $29 /$ 03 a 29/04/2004 em área experimental localizada no município de ItumirimMG. Plantas de capim-limão com cerca de 12 meses de idade tiveram suas folhas colhidas pela manhã, sendo então levadas imediatamente ao laboratório da UFLA para seleção e pesagem. Em seguida, as folhas inteiras foram colocadas em sacos de papel Kraft e levadas aos respectivos tratamentos de secagem: em estufa de circulação forçada mantida a $40^{\circ} \mathrm{C}$ e em sala com desumidificador, até peso constante.

Após o período de secagem, a matéria seca foi fragmentada em três níveis: pulverização em moinho de facas utilizando tamis com malha de 20 mesh e cortada em fragmentos com 1 centímetro e com 20 centímetros de comprimento, para a imediata extração do óleo essencial.

A extração do óleo essencial das folhas de capim-limão foi realizada pelo processo de hidrodestilação durante 2 horas em aparelho de Clevenger modificado com $40 \mathrm{~g}$ de matéria seca. Em seguida, o hidrolato foi submetido à partição líquido-líquido, em funil de separação, utilizandose $30 \mathrm{ml}$ de diclorometano. Este procedimento foi realizado por três vezes. A fração orgânica foi reunida e adicionou-se $3 \mathrm{~g}$ de sulfato de magnésio anidro para retirar possíveis resíduos de água. Após $30 \mathrm{~min}$ de repouso, a solução foi filtrada por meio de filtração simples e armazenada à temperatura ambiente em vidros escuros parcialmente tampados para permitir a evaporação do solvente à temperatura ambiente sob capela de exaustão de gases. Em seguida foram determinadas as massas dos óleos, a fim de obter os rendimentos extrativos.

Amostras do óleo foram analisadas em cromatógrafo de gás acoplado a espectrômetro de massa (GC-MS) Shimadzu QP5050A nas seguintes condições: coluna CBP-5 (Shimadzu) preenchida com coluna capilar de sílica (30 $\mathrm{m} \times 0,25 \mathrm{~mm}$ diâmetro interno x 0,25 $\mu \mathrm{m}$, filme composto de fenilmetilpolisiloxano 5\%) conectado a um detetor quadrupólo operando em modo EI a $70 \mathrm{eV}$ com intervalo de massa entre $40-400 \mu$, a razão de $0,5 \mathrm{scan} / \mathrm{s}$; gás carreador: $\mathrm{He}(1 \mathrm{ml} / \mathrm{min})$; injetor e temperatura de interface a $220^{\circ} \mathrm{C}$ e $240^{\circ} \mathrm{C}$, respectivamente, com razão de fluxo 1:20. O volume de injeção foi de $0,2 \mu \mathrm{l}\left(20 \% \mathrm{em} \mathrm{CH}_{2} \mathrm{Cl}_{2}\right)$ em fluxo e temperatura de $60^{\circ} \mathrm{C}$ a $246^{\circ} \mathrm{C}$, com um aumento de $3^{\circ} \mathrm{C} / \mathrm{min}$, após $10^{\circ} \mathrm{C} / \mathrm{min}$ para $270^{\circ} \mathrm{C}$, mantendo a temperatura final por 5 min. Os componentes foram identificados por comparação com dados de espectro de massa da literatura (ADAMS, 2001) e por base de dados computadorizada usando biblioteca NIST (1998). As concentrações dos compostos foram calculadas a partir das áreas dos picos e expressos com valores aferidos em três análises.

$\mathrm{O}$ delineamento experimental adotado foi o de blocos casualizados com 4 repetições, em esquema fatorial $2 \times 3$. Os resultados de rendimento foram expressos em $\mathrm{g} \mathrm{kg}^{-1}$ de matéria seca e analisados pelo software SISVAR para comparação de médias através do teste de Tukey a $5 \%$.

A composição química dos óleos não pôde ser comparada estatisticamente pelo teste de Tukey, pois foi analisada somente uma amostra composta formada pelo agrupamento das repetições de cada tratamento.

\section{RESULTADOS E DISCUSSÃO}

O processo de secagem da biomassa de capim-limão reduziu cerca de 5 vezes o peso da matéria fresca. A secagem dos fragmentos de 1 e $20 \mathrm{~cm} \mathrm{em}$ desumidificador proporcionou maior rendimento de óleo essencial do que em estufa, ao passo que no estado de pó não houve efeito significativo do método de secagem (Tabela 1). Embora outros trabalhos com secagem de capim-limão recomendem o uso de secagem em estufa com temperaturas variando entre 30 e $50^{\circ} \mathrm{C}$ para o maior rendimento e composição química do óleo (BUGGLE et al., 1999), no presente trabalho, a secagem das folhas em desumidificador, proporcionou maiores rendimentos na quantidade e composição do óleo em comparação com o uso da estufa mantida a $40^{\circ} \mathrm{C}$.

O rendimento de óleo variou em função dos diferentes tamanhos de fragmentos da matéria seca, apenas quando secos em estufa. De acordo com a Tabela 1 , observou-se que a matéria seca 
Tabela 1. Rendimento médio de óleo essencial ( $\mathrm{g} \mathrm{kg}^{-1}$ de matéria seca) de $C$. citratus em função de métodos de secagem e tamanho dos fragmentos da matéria seca. Lavras, UFLA, 2004.

\begin{tabular}{lrrrrc}
\hline \multirow{2}{*}{ Secagem } & \multicolumn{5}{c}{ Tamanho do Fragmento } \\
\cline { 2 - 6 } & $\mathbf{2 0} \mathbf{~ c m}$ & $\mathbf{1 ~} \mathbf{~ m}$ & pó $^{\text {* }}$ \\
\hline Estufa & 9,267 & bB & 8,148 & bB & 13,393 aA \\
Desumidificador & 13,605 & aA & 14,525 & aA & 13,540 aA \\
\hline
\end{tabular}

*Médias seguidas de mesma letra minúscula na coluna e maiúscula na linha, não diferem entre si a 5\% de probabilidade pelo teste Tukey.

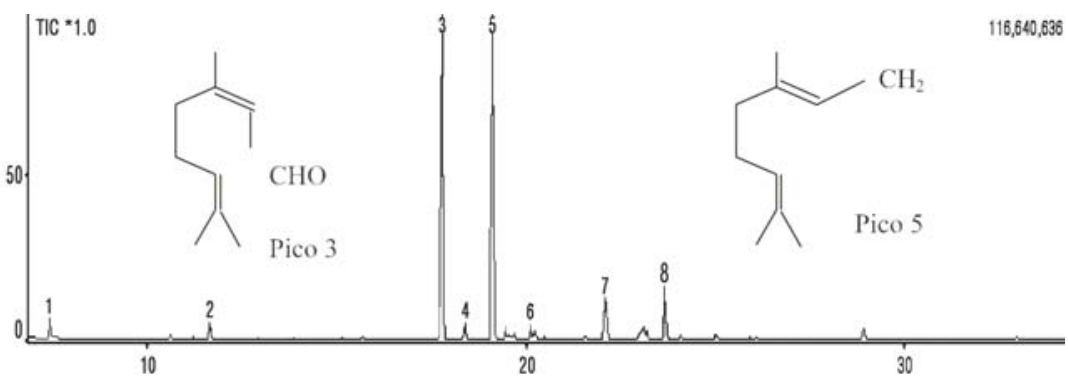

Figura 1. Cromatograma do óleo essencial de C. citratus.

Tabela 2. Composição química média (\%) dos óleos essenciais de C. citratus em função de métodos de secagem e fragmentação da matéria seca. Goiás, UFG, 2004.

\begin{tabular}{|c|c|c|c|c|c|c|}
\hline \multirow{2}{*}{ Componente } & \multicolumn{3}{|c|}{ Estufa } & \multicolumn{3}{|c|}{ Desumidificador } \\
\hline & $20 \mathrm{~cm}$ & $1 \mathrm{~cm}$ & pó & $20 \mathrm{~cm}$ & $1 \mathrm{~cm}$ & pó \\
\hline 6-metil-5-hepten-2-ona & $\mathrm{t}$ & $\mathrm{t}$ & 1,37 & $\mathrm{t}$ & 1,09 & $\mathrm{~T}$ \\
\hline linalol & 1,42 & 1,14 & 1,49 & 1,37 & 1,74 & 1,37 \\
\hline neral & 30,01 & 34,55 & 39,25 & 38,36 & 38,57 & 36,66 \\
\hline geraniol & $\mathrm{t}$ & 1,46 & 1,74 & 1,55 & 1,65 & 1,52 \\
\hline geranial & 39,59 & 44,50 & 43,80 & 46,06 & 45,44 & 45,7 \\
\hline epóxido linaloolóxido & 12,39 & 4,97 & 0,63 & $\mathrm{t}$ & $\mathrm{t}$ & 3,61 \\
\hline 2-undecanona & 9,49 & 1,40 & 1,23 & 1,20 & 1,39 & 1,79 \\
\hline tridecanona & $\mathrm{t}$ & 1,17 & 1,09 & 0,87 & $\mathrm{t}$ & 1,87 \\
\hline não identificados & 2,74 & 8,04 & 9,39 & 10,57 & 10,12 & 5,21 \\
\hline (citral $=$ neral + geranial & 69,60 & 79,05 & 83,05 & 84,42 & 84,01 & 82,36 \\
\hline
\end{tabular}

reduzida a pó proporcionou maior rendimento de óleo do que os fragmentos com 1 e $20 \mathrm{~cm}$ de comprimento.

A localização dos óleos essenciais nas plantas varia de acordo com a família botânica a qual pertence, podendo ocorrer em estruturas secretoras especializadas, tais como pêlos ou tricomas glandulares (Lamiaceae), corpos oleíferos (Apiaceae), bolsas lisígenas ou esquizolisígenas (Pinaceae, Rutaceae) ou células parenquimáticas diferenciadas (Lauraceae, Piperaceae e Poaceae), como é o caso do capim-limão (SIMÕES; SPITZER, 2000; LEWINSOHN et al., 1998). No presente trabalho, provavelmente o desumidificador reduziu a perda de óleo destas células parenquimáticas, contribuindo para um maior rendimento de óleo essencial. Possivelmente a menor temperatura no desumidificador e a secagem do material em função da desidratação do ambiente preservou essas células parenquimáticas, em comparação com a estufa, que mantém temperatura relativamente alta $\left(40^{\circ} \mathrm{C}\right)$.

A análise qualitativa do óleo essencial de $C$. citratus, mostra que os componentes majoritários presentes no óleo foram o neral e o geranial (Figura 1). A mistura destes dois isômeros forma o citral, principal constituinte do óleo essencial de $C$. citratus (SOUSA et al., 1991).

A composição química do óleo essencial de $C$. citratus em função dos métodos de secagem e fragmentação da matéria seca encontra-se na Tabela 2. Observa-se que houve variação no conteúdo de citral em função do método de secagem e fragmentação da matéria seca. Na secagem em desumidificador o conteúdo de citral foi maior em relação à secagem em estufa. Temperaturas menores no desumidificador contribuíram para uma menor degradação das células oleíferas e conseqüentemente, preservando os componentes químicos do óleo. No tocante à fragmentação, observou-se que na secagem em desumidificador, o conteúdo de citral foi em média $8,25 \%$ superior do que na secagem em estufa (Tabela 2).

$\mathrm{Na}$ secagem em estufa, o conteúdo de citral variou em função da fragmentação, sendo que na forma de pó, o conteúdo de citral foi em média 19,3\% maior que na fragmentação de $20 \mathrm{~cm}$ e $5,06 \%$ maior em relação ao corte de 1 $\mathrm{cm}$. Porém, para a secagem em desumidificador, o efeito da fragmentação foi menor. A diferença no conteúdo de citral entre o corte de $20 \mathrm{~cm}$ e a redução a pó foi de apenas $2,5 \%$, em comparação às diferenças obtidas na secagem em estufa. Conforme Lewinsohn et al. (1998), o acúmulo de citral em $C$. citratus ocorre em células oleíferas com paredes celulares lignificadas existentes no mesofilo próximo aos feixes vasculares. A pulverização do material permitiu um aumento da superfície de contato do material vegetal no processo de hidrodestilação e portanto uma maior extração dos óleos essenciais contidos nestas estruturas mais profundas.

Os compostos voláteis são muito sensíveis ao processo de secagem. Alterações na concentração de compostos voláteis durante a secagem podem ser afetadas por vários fatores como o método de secagem e as características do produto submetido à secagem (VENSKUTONIS, 1997).

$\mathrm{Na}$ secagem em desumidificador ocorreu a desidratação do material vegetal apenas pela redução da umidade do ar sem elevação da temperatura do ambiente preservando desta forma, as características originais da planta. Diante do exposto, pode-se verificar que o desumidificador é um aparelho eficien- 
te, de custo reduzido e econômico no uso da energia elétrica em comparação à estufa, representando desta forma, uma vantagem do ponto de vista prático.

Várias pesquisas em pós-colheita de plantas medicinais normalmente preocupam-se apenas com o efeito da temperatura de secagem no rendimento e qualidade do óleo essencial (BLANCO et al., 2002a, BLANCO et al., 2002b, MARTINS, 2000, RADÜNZ et al., 2002, ROCHA et al., 2000, VENSKUTONIS, 1997). Neste estudo, pôde-se perceber que o tamanho do fragmento do material vegetal submetido à extração de óleos essenciais também influencia o rendimento extrativo. Assim, considerando-se a variabilidade da localização dos óleos essenciais nas diferentes famílias de plantas sugere-se a realização de novos trabalhos levandose em consideração também a importante contribuição do tamanho do fragmento de matéria seca no rendimento extrativo do óleo essencial das plantas medicinais.

\section{LITERATURA CITADA}

ADAMS, R.P. Identification of essential oil components by gas chromatography/quadrupole mass sprestroscopy. Allured: Illinois, 2001. 421 p. BLANCO, M.C.S.G.; MING, L.C.; MARQUES, M.O.M.; BOVI, O.A. Drying temperature effects in Peppermint essential oil content and composition. Acta Horticulturae, n.569, p.95-98, 2002a. BLANCO, M.C.S.G.; MING, L.C.; MARQUES, M.O.M.; BOVI, O.A. Drying temperature effects in Rosemary essential oil content and composition. Acta Horticulturae, n.569, p.99-103, 2002 b.
BUGGLE, V.; MING, L.C.; MARQUES, M.O.M.; FURTADO, E.; ROCHA, S.F.R. Influence of different drying-temperatures on the amount of essential oils and citral content in Cymbopogon citratus (DC.) Stapf. - POACEAE. Acta Horticulturae, n.500, p.71-74, 1999.

CORRÊA JÚNIOR, C.; MING, L.C.; SCHEFFER, M.C. Cultivo de plantas medicinais, condimentares e aromáticas. 2 ed. Jaboticabal: FUNEP, 1994. 162 p.

CORRÊA, R.M.; BERTOLUCCI, S.K.V.; PINTO, J.E.B.P.; REIS, E.S.; ALVES, T.L. Rendimento de óleo essencial e caracterização de folhas de assapeixe submetidas a diferentes métodos de secagem. Ciência e Agrotecnologia, Lavras, v.28, n.2, p.341-346, 2004.

FERREIRA, M.S.C. Estudo farmacológico do Cymbopogon citratus (D.C.) Stapf. 1984. 93 p. Dissertação (Mestrado) - UFC, Ceará.

LEWINSOHN, E.; DUDAI, N.; TADMOR, Y.; KATZIR, I.; RAVID, U.; PUTIEVSKY, E., JOEL, D.M. Histochemical localization of citral accumulation in lemongrass leaves (Cymbopogon citratus (DC) Stapf., Poaceae). Annals of Botany, v.81, p.35-39, 1998

MARTINS, E.R.; CASTRO, D.M.; CASTELLANI, D.M.; DIAS, J.E. Plantas Medicinais. Viçosa: Editora UFV, 1998. 220 p

MARTINS, P.M. Influência da temperatura e da velocidade do ar de secagem no teor e na composição química do óleo essencial de capim-limão (Cymbopogon citratus (D.C.) Stapf.). 2000. $78 \mathrm{f}$. Dissertação (Mestrado em Engenharia Agrícola) - UFV, Viçosa

NATIONAL INSTITUTE OF STANDARDS AND TECHNOLOGY. PC version of the NIST/ EPA/NIH Mass Spectral Database. U.S. Department of Commerce, Gaithersburg, MD, 1998.

ONAWUNMI, G.O.; YISAK, W.A.B.; OGUNLANA, E.O. Antibacterial constituents in the essential oil of Cymbopogon citrates (DC.) Stapf. Journal of Ethnopharmacology, v.12, p.279286, 1984
RADÜNZ, L.L.; MELO, E.C.; MARTINS, P.M.; SANTOS, R.H.S.; SANTOS, R.R.; MACHADO, M.C. Secagem de alecrim-pimenta (Lippia sidoides, Cham.) em secador de leito fixo. Revista Brasileira de Plantas Medicinais, v.5, n.1, p.7982, 2002.

ROCHA, S.F.R.; MING, L.C.; MARQUES, M.O.M. Influência de cinco temperaturas de secagem no rendimento e composição do óleo essencial de citronela (Cymbopogon winterianus Jowit). Revista Brasileira de Plantas Medicinais, v.3, n.1, p.73-78, 2000.

ROSAL, L.F.; PINTO, J.E.B.P.; BERTOLUCCI, S.K.V.; SOARES, G.A.; BARROS, T.A. Teor de óleo essencial de folhas e inflorescências de basilicão sob diferentes métodos de secagem. In: CONGRESSO DOS PÓS-GRADUANDOS DA UFLA, 8. 2004, Lavras. Anais... Lavras, 2004 p.23.

SILVA, R.; PINTO, J.E.B.P.; BERTOLUCCI, S.K.V.; DINIZ, K.A. Teores de óleos essenciais de folhas frescas e secas em diferentes estados de divisão de cidrão (Aloysia triphylla (L'Hérit) Britton)). In: CONGRESSO DOS PÓSGRADUANDOS DA UFLA, 8. 2004, Lavras. Anais... Lavras, 2004. p.43.

SIMÕES, C.M.O.; SPITZER, V. Óleos voláteis. In: SIMÕES, C.M.O. et al. Farmacognosia: da planta ao medicamento. 2 ed. Porto Alegre/ Florianópolis: Ed. Universidade/UFRGS/Ed. UFSC, 2000. p.387-416.

SOUSA, M.P.; MATOS, M.E.O.; MATOS, F.J.A.; MACHADO, M.I.L.; CRAVEIRO, A.A. Constituintes químicos ativos de plantas medicinais brasileiras. Fortaleza: Edições UFC, Laboratório de Produtos Naturais, 1991. $416 \mathrm{p}$.

VENSKUTONIS, P.R. Effect of drying on the volatile constituints of thyme (Thymus vulgaris) And sage (Salvia officinalis L.). Food Chemistry, v.59, n.2, p.219-277, 1997

VON HERTWIG, I.F. Plantas aromáticas e medicinais: plantio, colheita, secagem, comercialização. 2 ed. São Paulo: Ícone, 1991. $414 \mathrm{p}$. 